\title{
HUBUNGAN KETERSEDIAAN AIR TANAH DAN SIFAT-SIFAT DASAR FISIKA TANAH
}

\section{Relationship between Soil Moisture Availability and Basic Soil Physical Properties}

\author{
K. Murtilaksono* dan E.D. Wahyuni
}

Departemen Tanah, Fakultas Pertanian, Institut Pertanian Bogor Jalan Meranti, Kampus IPB Darmaga, Bogor 16680

\begin{abstract}
This research was conducted to study relationship between soil moisture content and soil physical characteristics that affected the moisture.

The soil samples were collected from 22 scattered sites of West Java and Central Java. Analysis of soil physical properties (texture, bulk density, particle density, total porosity and soil moisture retention) and soil chemical property (organic matter) was conducted at the laboratory of Department of Soil Sciences, Faculty of Agriculture, Bogor Agricultural University. Analysis of simple linier regression was applied to know the correlation between soil moisture content and other basic soil physical properties.

Availability of soil moisture ( $p F 4.20$ - pF 2.54) significantly correlated with organic matter, total porosity, and micro pores. The higher organic matter content as well as total porosity and micro pores the higher available soil moisture. Soil moisture of field capacity significantly correlated with clay content, sand content, micro and macro pores. The higher clay content and micro pores the higher soil moisture of field capacity. In the contrary, the higher macro pores and sand content the lower the field capacity. Soil moisture of wilting point significantly correlated with clay content and macro pores. The higher clay content the higher the wilting point, while the higher macro pores the lower soil moisture of wilting point.
\end{abstract}

Keywords : Available soil water, field capacity, organic matter, soil pores, wilting point

\section{PENDAHULUAN}

Keberadaan air di dalam pori-pori tanah atau diistilahkan sebagai kelembaban atau kadar air tanah sangat dipengaruhi oleh adanya proses adhesi antara air dan tanah, proses kohesi antara molekul-molekul air itu sendiri, dan gaya gravitasi yang bekerja pada air tersebut. Semakin sedikit air yang ada di dalam pori-pori tanah semakin kuat air tersebut ditahan oleh matrik tanah oleh gaya adesi dan kohesi, sedangkan air yang tidak tertahan oleh matrik tanah akan terbuang atau hilang oleh gaya gravitasi sebagai air drainase.

Air drainase yang umumnya menempati pori-pori makro tanah dapat diketahui dengan perhitungan dari penetapan kadar air pada $\mathrm{pF} 1.00, \mathrm{pF} 2.00$, dan $\mathrm{pF} 2.54$ serta porositas total tanah. Air dalam pori-pori tanah yang tidak dipengaruhi oleh gaya gravitasi lagi atau berlawanan sama dengan gaya gravitasi disebut air pada kapasitas lapang yang dapat didekati dengan $\mathrm{pF} 2.54$ (setara dengan kadar air tanah pada tegangan 1/3 atm). Air yang sangat kuat ditahan oleh matrik tanah sehingga sudah tidak dapat diserap oleh akar tanaman disebut sebagai air pada titik layu permanen yang dapat didekati dengan $\mathrm{pF} 4.20$ (setara dengan kadar air pada tegangan 15 atm). Selang antara kadar air kapasitas lapang dan kadar air titik layu permanen

*Alamat korespondensi: e-mail: murtilaksono@yahoo.com disebut air tersedia bagi tanaman. Selanjutnya, nilai air tersedia dapat digunakan untuk penetapan kebutuhan air irigasi (Hilel, 1980). Kelembaban tanah berhubungan dengan luas permukaan partikel tanah dan volume ruang pori, sehingga kelembaban tanah berhubungan dengan tekstur dan struktur tanah (Foth dan Turk, 1972). Secara umum, tekstur, struktur dan kadar bahan organik tanah mempengaruhi jumlah air tersedia bagi tanaman (Buckman dan Brady, 1971).

Setiap jenis tanah dengan kelas tekstur yang berbeda nyata akan mempunyai distribusi ukuran pori yang berbeda dan akan berpengaruh terhadap karakteristik atau perilaku kelembaban tanah yang berbeda pula. Begitu juga tanah yang bertekstur sama apabila berbeda strukturnya akan memiliki karakter kelembaban tanah yang berbeda pula. Tanah berstruktur berbeda memiliki distribusi ukuran pori berbeda. Di samping itu, kelembaban tanah juga dipengaruhi tentunya sifat-sifat dasar fisika tanah lainnya. Oleh karena itu, tanah-tanah yang berbeda jenisnya akan memiliki karakteristik kelembaban tanah yang berbeda apabila karakteristik dasar fisika tanah berbeda. Sifat-sifat dasar fisika tanah merupakan sifat fisika tanah yang hakiki atau bukan merupakan suatu proses fisika tanah seperti evaporasi, infiltrasi, perambatan suhu dan gas.

Penelitian ini bertujuan untuk mempelajari hubungan karaketristik kelembaban tanah dan sifat-sifat dasar fisika tanah dari berbagai jenis tanah yang memiliki sifat-sifat fisika berbeda. 


\section{BAHAN DAN METODE}

Contoh-contoh tanah penelitian yang dianalisis di laboratorium untuk penetapan sifat fisika tanah dan kadar bahan organik diambil dari berbagai lokasi di Jawa Barat dan Jawa Tengah yang mewakili berbagai jenis tanah dan sifat fisika tanah yang relatif berbeda nyata.

Analisis tanah dilakukan di laboratorium Departemen Tanah, Fakultas Pertanian, Institut Pertanian Bogor. Analisis tanah yang dilakukan meliputi analisis tekstur, penetapan bobot isi tanah, bobot jenis partikel, pengukuran porositas total, pengukuran retensi air tanah, dan bahan organik tanah. Metode analisis tanah disajikan pada Tabel 1.

Analisis statistik yang digunakan dalam penelitian ini adalah analisis regresi linear sederhana, yaitu dengan uji $\mathrm{Z}$ untuk mengetahui linier atau tidaknya hubungan peubah bebas dan tidak bebas. Tingkat pengaruh peubah bebas terhadap peubah tak bebas dinyatakan dengan koefisien korelasi (R). Selanjutnya untuk mengetahui nyata tidaknya pengaruh peubah bebas diuji dengan uji $\mathrm{F}$ pada taraf $5 \%$.

Tabel 1. Metode yang Digunakan untuk Menganalisis Sifat Fisik Tanah

\begin{tabular}{|c|c|c|}
\hline No & Parameter & Metode \\
\hline 1 & Tekstur & Pipet \\
\hline 2 & Bobot isi (BI) & Gravimetri (ring sampel) \\
\hline 3 & $\begin{array}{l}\text { Kerapatan Jenis Zarah } \\
(\mathrm{KJZ})\end{array}$ & Gravimetri (piknometer) \\
\hline 4 & $\begin{array}{l}\text { Porositas Total, Pori } \\
\text { drainase }\end{array}$ & $\begin{array}{l}\text { Perhitungan dengan rumus (BI, KJZ, } \\
\text { kurva } \mathrm{pF} \text { ) }\end{array}$ \\
\hline 6 & $\begin{array}{l}\text { Status kelembaban } \\
\operatorname{tanah}(\mathrm{pF})\end{array}$ & $\begin{array}{l}\text { Gravimetri (pressure plate \& } \\
\text { membrane apparatus) }\end{array}$ \\
\hline 7 & Bahan organik & Walkley dan Black \\
\hline
\end{tabular}

\section{HASIL DAN PEMBAHASAN}

Hasil analisis kadar air (kelembaban) tanah pada berbagai tekanan $(\mathrm{pF})$ dan penetapan beberapa sifat fisika tanah lainnya pada berbagai jenis tanah disajikan pada Tabel 2. Jenis-jenis tanah tersebut relatif mewakili kelas tekstur kasar (berpasir) hingga halus (berliat). Hasil analisis uji korelasi menunjukkan bahwa kadar air tersedia ( $\mathrm{pF} 4.20$ - $\mathrm{pF} 2.54$ ) nyata berkorelasi positif dengan bahan organik, ruang pori total dan pori mikro (Tabel 3).

Semakin tinggi bahan organik, ruang pori total dan pori mikro tanah, semakin tinggi kadar air tersedia tanah. Bahan organik mempunyai kemampuan menyerap air yang tinggi sehingga tanah yang berbahan organik tinggi akan mempunyai kemampuan menyimpan air tinggi pula (Bauer dan Black, 1992; Dao, 1993). Kandungan kelembaban tanah pada tegangan tertentu dapat dipengaruhi antara lain oleh kadar bahan organik tanah serta jumlah dan ukuran pori tanah (Buckman dan Brady, 1971). Jika air yang dipegang bahan organik tanah tidak menguap maka air tersebut tersedia bagi tanaman untuk fotosintesis dan proses fisiologis lainnya. Nilai koefisien korelasi nyata positif antara kadar air tersedia dan kadar bahan organik tanah dengan nilai sebesar 0.53 seperti tersaji pada Gambar 1 dan Tabel 3 .

Kadar air tersedia tanah adalah sejumlah air yang berada di pori tanah karena potensial matrik tanah setelah potensial gravitasi tidak bekerja lagi pada air dalam pori tanah tersebut, dan air tanah tersebut masih dapat diserap oleh akar tanaman. Semakin tinggi kadar liat tanah semakin tinggi pori-pori mikro dibandingkan pori-pori makro. Pada pori-pori mikro air lebih mudah dijerap oleh matrik tanah dari pada pori-pori makro di mana air akan lebih banyak hilang karena proses gravitasi dan sedikit dapat dijerap oleh matrik tanah (Nimmo, 1997; Jones dan Dani, 1998). Dengan demikian, sesuai dengan pernyataan Jury et al. (1991) bahwa semakin tinggi kadar liat tanah semakin tinggi jumlah pori mikro sehingga kadar air tersedia juga akan semakin tinggi secara nyata berdasarkan uji $\mathrm{F}\left(\mathrm{R}=0.45^{*}\right)$, demikian juga semakin banyak pori mikro tanah, maka secara nyata semakin besar pula ruang pori totalnya $\left(\mathrm{R}=0.65^{*}\right)$. Walaupun demikian, kadar liat dan pasir tanah tidak nyata berkorelasi dengan kadar air tersedia tanah $(\mathrm{R}=0.06$ dan $\mathrm{R}=-0.13)$. Hubungan kadar air tersedia tanah dengan pori mikro dan ruang pori total masing-masing disajikan pada Gambar 2 dan 3.

Kadar air kapasitas lapang adalah air yang berada dalam pori-pori tanah dan tidak terpengaruhi lagi oleh gaya gravitasi, kecuali gaya matrik tanah (Hanks dan Ashcroft, 1980). Semakin banyak pori-pori mikro tanah $(\mathrm{R}=0.67 *)$ yang merupakan cerminan dari tingginya kadar liat tanah $(\mathrm{R}=0.62 *)$, maka berdasarkan uji $\mathrm{F}$ semakin nyata banyaknya air yang dapat dijerap oleh matrik tanah dan tidak terdrainase karena gaya gravitasi. Sebaliknya, semakin tingginya kadar pasir yang menyebabkan tingginya pori-pori makro tanah maka akan semakin menurunkan kadar air kapasitas lapang $(\mathrm{R}=-0.51 *$ dan $\mathrm{R}=-0.54 *)$. Kadar air kapasitas lapang sangat dipengaruhi oleh proporsi kandungan pasir dan liat atau tekstur tanah (Thompson dan Troeh, 1978; Foth dan Turk, 1972).

Kadar air pada titik layu permanen adalah air yang dijerap kuat oleh gaya matrik tanah sehingga sudah tidak dapat diserap oleh akar tanaman lagi atau tidak tersedia bagi tanaman. Gaya atau potensial matrik air tanah pada partikel liat jauh lebih besar dibandingkan potensial matrik air pada partikel pasir. Koefisien korelasi positif nyata kadar liat tanah terhadap kadar air titik layu permanen menunjukkan nilai 0.59, sedangkan koefisien korelasi negatif nyata pori makro yang merupakan cerminan tingginya kadar pasir tanah terhadap kadar air titik layu permanen menunjukkan nilai -0.55. Semakin tinggi kadar liat maka semakin tinggi kadar air titik layu permanen sebaliknya semakin tinggi pori-pori makro tanah semakin rendah kadar air titik layu permanen karena luas permukaan partikel tanah semakin kecil. 
Tabel 2. Kadar Air Tanah pada Berbagai Hisapan dan Beberapa Sifat Fisika Lainnya pada Berbagai Jenis Tanah

\begin{tabular}{|c|c|c|c|c|c|c|c|c|c|c|c|c|c|c|c|}
\hline \multirow[t]{2}{*}{ No } & \multirow[t]{2}{*}{ Jenis Tanah } & $\begin{array}{c}\mathrm{pF} \\
1.00\end{array}$ & $\begin{array}{c}\mathrm{pF} \\
2.00\end{array}$ & $\begin{array}{c}\mathrm{pF} \\
2.54\end{array}$ & $\begin{array}{c}\mathrm{pF} \\
4.20\end{array}$ & $\begin{array}{c}\text { Air } \\
\text { T'dia }\end{array}$ & Pasir & Debu & Liat & BI & $\mathrm{KJZ}$ & RPT & $\begin{array}{c}\text { Pori } \\
\text { Makro }\end{array}$ & $\begin{array}{l}\text { Pori } \\
\text { Mikro }\end{array}$ & BO \\
\hline & & \multicolumn{5}{|c|}{$\ldots \ldots \ldots \ldots \ldots \ldots \ldots \ldots \ldots \ldots$} & \multicolumn{3}{|c|}{ 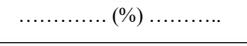 } & \multicolumn{2}{|c|}{$\ldots\left(\mathrm{g} \mathrm{cm}^{-3}\right) \ldots \ldots$} & \multicolumn{3}{|c|}{$\ldots \ldots \ldots \ldots\left(\mathrm{v}^{-1}\right) \ldots \ldots \ldots$} & $\ldots(\%) .$. \\
\hline 1 & Aluvial Brebes & 64.79 & 58.61 & 51.53 & 25.10 & 26.43 & 3.57 & 20.17 & 76.26 & 1.16 & 2.60 & 55.33 & 13.26 & 42.06 & 1.57 \\
\hline 2 & Aluvial Kerawang & 51.78 & 44.12 & 36.58 & 33.07 & 3.51 & 15.38 & 44.90 & 39.73 & 1.64 & 2.51 & 34.68 & 15.20 & 19.48 & 3.11 \\
\hline 3 & Latosol Alas Roban & 45.51 & 41.65 & 38.20 & 24.37 & 13.83 & 23.55 & 22.75 & 53.70 & 1.24 & 2.61 & 52.34 & 14.16 & 38.18 & 3.31 \\
\hline 4 & Latosol Bumi Serpong Damai & 52.01 & 49.54 & 43.63 & 34.08 & 9.55 & 10.08 & 10.86 & 79.06 & 1.07 & 2.38 & 54.90 & 11.25 & 43.65 & 2.59 \\
\hline 5 & Latosol Darmaga & 62.41 & 55.91 & 53.36 & 29.80 & 23.56 & 5.95 & 16.60 & 77.45 & 0.86 & 2.70 & 68.20 & 14.79 & 53.41 & 3.13 \\
\hline 6 & Latosol Klampok & 61.85 & 53.70 & 49.69 & 36.99 & 12.70 & 8.85 & 33.24 & 57.91 & 1.08 & 2.56 & 57.96 & 12.16 & 45.79 & 3.07 \\
\hline 7 & Latosol merah Gunung Sindur & 69.12 & 67.99 & 52.69 & 34.72 & 17.97 & 4.72 & 4.72 & 90.57 & 1.13 & 2.35 & 52.12 & 16.43 & 35.69 & 1.59 \\
\hline 8 & Latosol merah Jatiasih & 52.11 & 43.39 & 38.36 & 28.52 & 9.84 & 4.44 & 12.00 & 83.56 & 1.04 & 2.34 & 55.75 & 17.99 & 37.76 & 1.88 \\
\hline 9 & Latosol Sindangbarang & 55.47 & 46.11 & 44.42 & 30.08 & 14.34 & 21.51 & 24.65 & 53.84 & 0.96 & 2.29 & 58.02 & 13.53 & 44.49 & 4.54 \\
\hline 10 & Mediteran Ciampea & 59.67 & 56.79 & 52.46 & 34.13 & 18.33 & 10.21 & 15.13 & 74.65 & 1.05 & 2.38 & 55.71 & 07.20 & 48.50 & 2.03 \\
\hline 11 & Mediteran Padalarang & 74.17 & 56.52 & 49.69 & 46.67 & 3.02 & 9.13 & 10.10 & 80.77 & 1.38 & 2.60 & 46.90 & 24.49 & 22.42 & 1.79 \\
\hline 12 & Podzolik Jasinga & 78.42 & 58.35 & 57.75 & 51.75 & 6.00 & 7.77 & 10.68 & 81.55 & 1.11 & 2.53 & 56.27 & 20.66 & 35.60 & 2.45 \\
\hline 13 & Podzolik Serang & 39.26 & 39.05 & 30.80 & 20.10 & 10.70 & 25.44 & 24.46 & 50.10 & 1.27 & 2.63 & 51.66 & 20.86 & 30.80 & 3.47 \\
\hline 14 & Podzolik Talang Betutu & 40.66 & 36.84 & 34.68 & 29.10 & 5.58 & 23.30 & 22.65 & 54.05 & 1.35 & 2.68 & 49.58 & 14.98 & 34.60 & 2.17 \\
\hline 15 & Grumosol Mranggen & 55.55 & 54.47 & 47.14 & 37.55 & 9.59 & 1.44 & 40.64 & 57.93 & 1.25 & 2.53 & 50.59 & 08.40 & 42.19 & 1.77 \\
\hline 16 & Grumusol Godong & 78.61 & 72.97 & 70.61 & 53.53 & 17.08 & 35.01 & 20.56 & 44.42 & 1.26 & 2.43 & 48.05 & 08.00 & 40.05 & 2.42 \\
\hline 17 & Andosol Ngadirejo & 58.45 & 53.32 & 47.45 & 14.82 & 32.63 & 44.38 & 24.42 & 31.20 & 0.66 & 2.58 & 74.30 & 26.84 & 47.45 & 8.38 \\
\hline 18 & Andosol Pengalengan & 60.07 & 51.94 & 44.52 & 9.17 & 35.35 & 32.77 & 36.64 & 30.59 & 0.53 & 2.48 & 78.58 & 34.06 & 44.52 & 12.09 \\
\hline 19 & Regosol Muntilan & 41.77 & 26.89 & 9.96 & 6.97 & 2.99 & 70.06 & 24.80 & 5.15 & 1.30 & 2.70 & 51.73 & 41.77 & 09.96 & 1.47 \\
\hline 20 & Regosol Laladon & 43.53 & 27.08 & 24.95 & 22.48 & 2.47 & 76.78 & 12.13 & 5.15 & 1.18 & 2.47 & 52.24 & 27.29 & 24.95 & 0.89 \\
\hline 21 & Planosol Serang & 44.86 & 37.54 & 30.75 & 10.32 & 20.43 & 6.65 & 49.06 & 44.30 & 1.39 & 2.39 & 41.86 & 14.11 & 27.75 & 3.46 \\
\hline 22 & Planosol Cikarang & 47.13 & 40.61 & 32.11 & 20.88 & 11.23 & 12.24 & 56.19 & 31.57 & 1.41 & 2.63 & 46.35 & 15.02 & 31.33 & 2.96 \\
\hline
\end{tabular}

Keterangan $: \mathrm{BI}=$ bobot isi; $\mathrm{KJZ}=$ kerapatan jenis zarah; $\mathrm{RPT}=$ ruang pori total; $\mathrm{BO}=$ bahan organik

Tabel 3. Koefisien Korelasi Kadar Air Tanah dengan Faktor yang Mempengaruhinya

\begin{tabular}{ccccccc}
\hline Kadar Air Tanah & $\begin{array}{c}\text { Bahan } \\
\text { Organik }\end{array}$ & $\begin{array}{c}\text { Ruang Pori } \\
\text { Total }\end{array}$ & $\begin{array}{c}\text { Pori } \\
\text { Makro }\end{array}$ & $\begin{array}{c}\text { Pori } \\
\text { Mikro }\end{array}$ & $\begin{array}{c}\text { Kadar } \\
\text { Liat }\end{array}$ & $\begin{array}{c}\text { Kadar } \\
\text { Pasir }\end{array}$ \\
\hline Air tersedia (pF 2.54-4.20) & $\mathbf{0 . 5 3 *}$ & $\mathbf{0 . 7 0 *}$ & -0.01 & $\mathbf{0 . 6 5 *}$ & 0.06 & -0.13 \\
Kapasitas lapang (pF 2.54) & 0.09 & 0.25 & $\mathbf{- 0 . 5 4 *}$ & $\mathbf{0 . 6 7 *}$ & $\mathbf{0 . 6 2 *}$ & $\mathbf{- 0 . 5 1 *}$ \\
Titik layu permanen (pF 4.20) & -0.43 & -0.27 & $\mathbf{- 0 . 5 5 *}$ & 0.20 & $\mathbf{0 . 5 9 *}$ & -0.43 \\
\hline
\end{tabular}




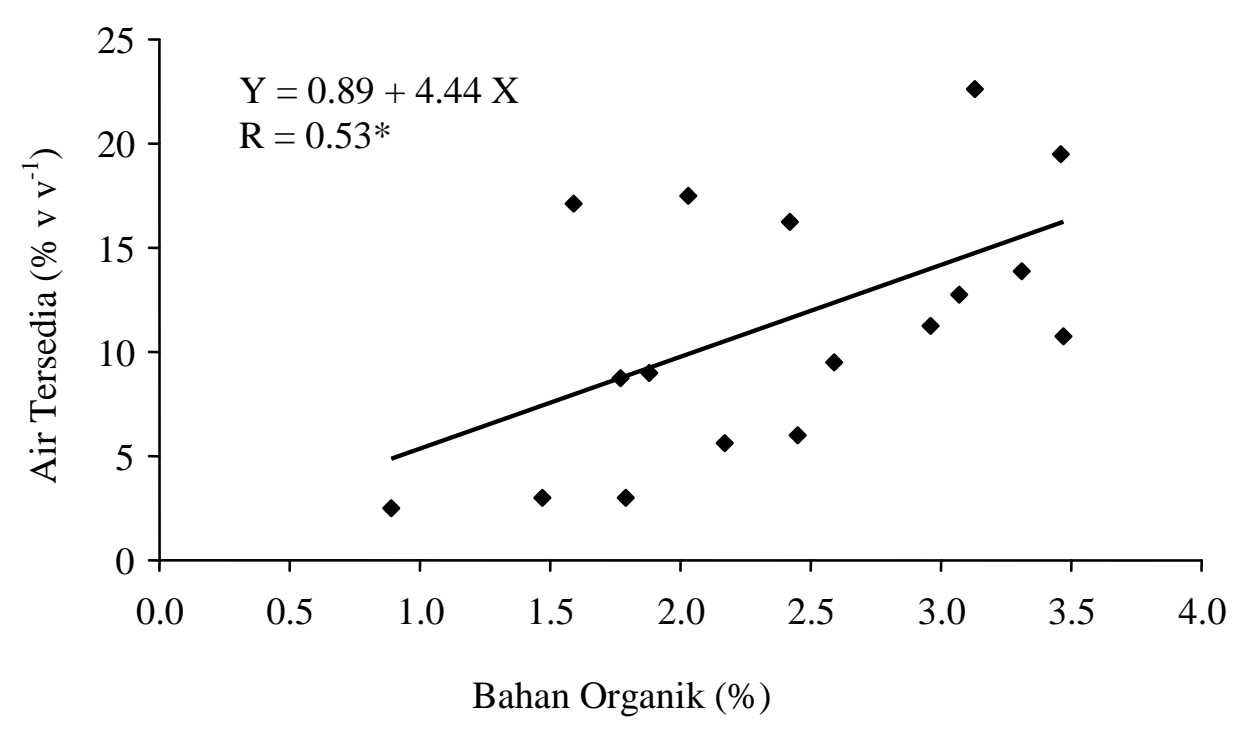

Gambar 1. Hubungan Kadar Air Tersedia dan Bahan Organik Tanah

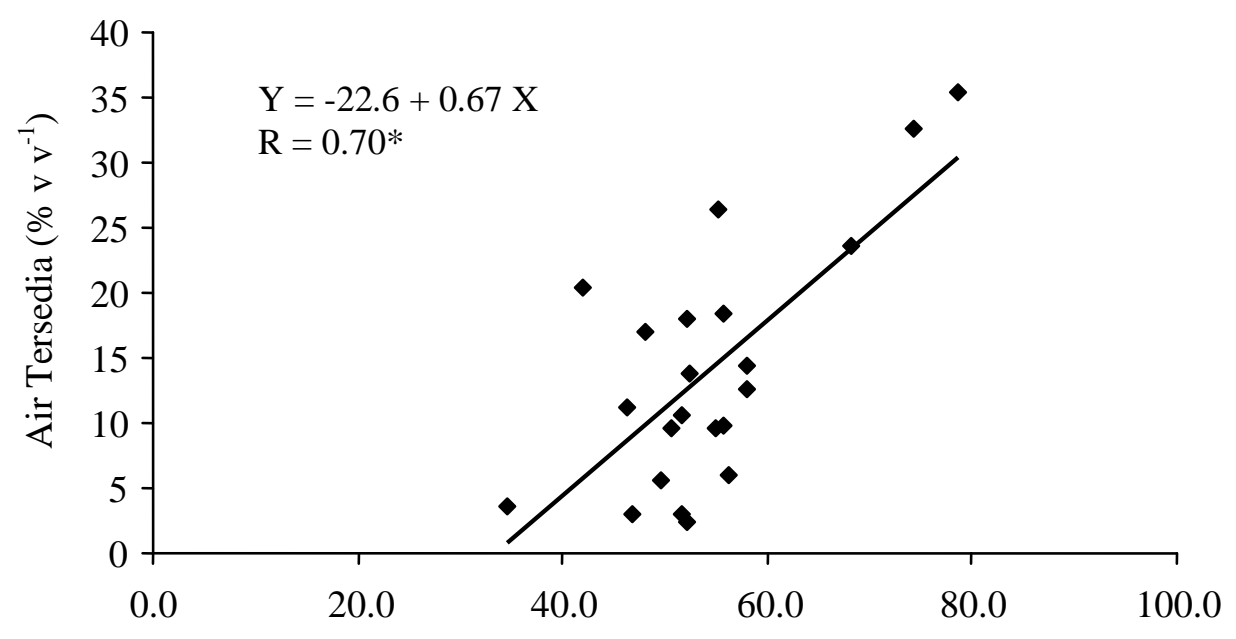

Ruang Pori Total (\%)

Gambar 2. Hubungan Kadar Air Tersedia dan Ruang Pori Total Tanah 


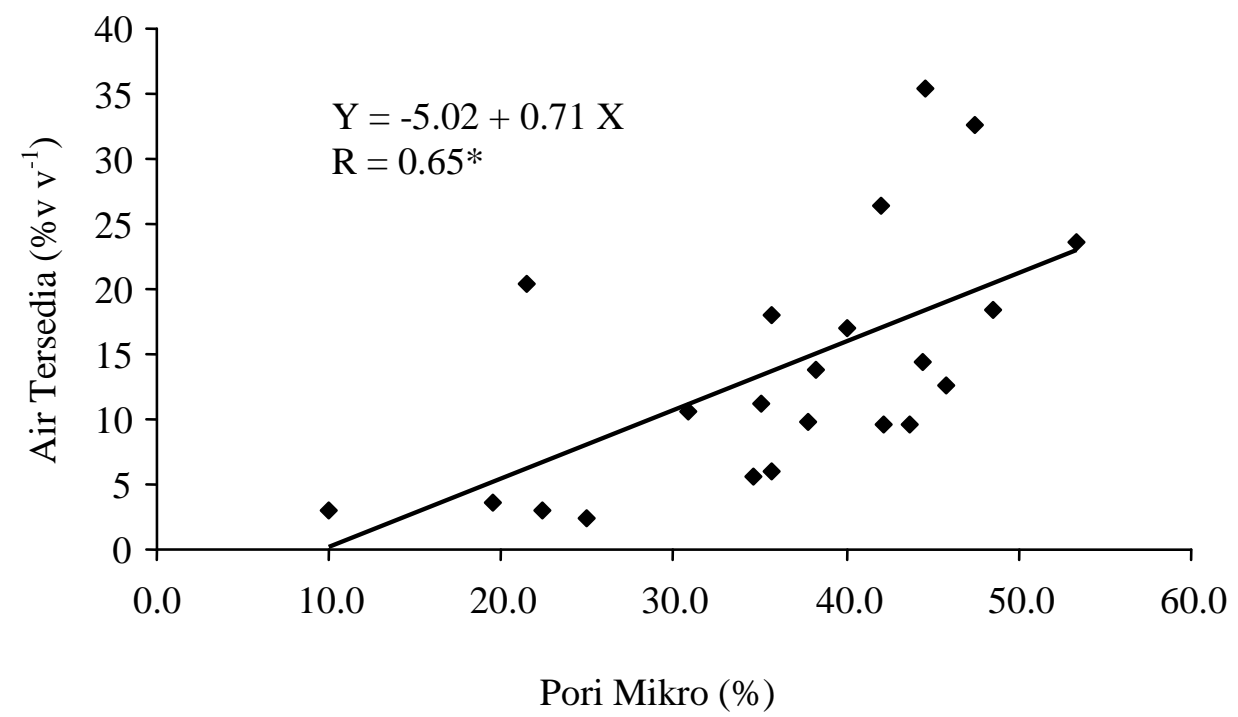

Gambar 3. Hubungan Kadar Air Tersedia dan Pori Mikro Tanah

\section{KESIMPULAN}

1. Kadar air tersedia ( $\mathrm{pF} 4.2-\mathrm{pF} 2.54)$ nyata berkorelasi positif dengan bahan organik, ruang pori total dan pori mikro (masing-masing $\mathrm{R}=0.53^{*}, \mathrm{R}=0.70^{*}$, dan $\mathrm{R}=$ $0.65 *)$. Semakin tinggi kandungan bahan organik, ruang pori total dan pori mikro tanah, maka semakin tinggi pula kadar air tersedia tanah.

2. Kadar air kapasitas lapang nyata berkorelasi dengan kadar liat, kadar pasir, pori-pori mikro dan pori-pori makro tanah (masing-masing $\mathrm{R}=0.62 *, \mathrm{R}=-0.51 * \mathrm{R}$ $=0.57 *$ dan $\mathrm{R}=-0.54 *$ ). Semakin tinggi kadar liat dan pori-pori makro tanah maka semakin tinggi kadar air kapasitas lapang, namun sebaliknya semakin tinggi pori-pori makro dan kadar pasir tanah maka semakin rendah kadar air kapasitas lapang.

3. Kadar air titik layu permanen nyata berhubungan dengan kadar liat dan pori-pori makro tanah (masingmasing $\mathrm{R}=0.59 *$ dan $\mathrm{R}=-0.55 *)$. Semakin tinggi kadar liat maka semakin tinggi kadar air titik layu permanen sebaliknya semakin tinggi pori-pori makro tanah semakin rendah kadar air titik layu permanen.

\section{UCAPAN TERIMA KASIH}

Penulis menyampaikan penghargaan dan terima kasih kepada saudara Iman Giyanto, Gunawan Kristiyanto, Dony Rusdi, dan Charles Larry, yang telah memberikan sumbangan tenaga dan pikirannya. Penulis juga mengucapkan terima kasih kepada QUE Project Departemen Tanah, Faperta IPB yang telah mendanai penelitian ini pada tahun 2003.

\section{DAFTAR PUSTAKA}

Bauer, A. and A.L. Black. 1992. Organic carbon effects on available water capacity of three textural groups. Soil Sci. Soc. Amer. J. 56 : 248-254.

Buckman, H.O. and N.C. Brady. 1971. The Nature and Properties of Soil. $7^{\text {th }}$ ed. The Mac Millan Co., Collier Mac Millan Ltd., London.

Dao, T.H. 1993. Tillage and winter wheat residual management effect on water infiltration and storage. Soil Sci. Soc. Amer. J. $57: 1586-1595$.

Foth, D.H. and L.M. Turk. 1972. Fundamental of Soil Science. $5^{\text {th }}$ ed. John Wiley \& Son, Inc., New York, London, Sydney, Toronto.

Hanks, R.J. and G.L. Ashcroft. 1980. Applied Soil Physics. Soil Water and Temperature Applications. Springer-Verlag. Berlin, New York.

Hilel, D. 1980. Fundamental of Soil Physics. Academic Press, New York, London, Toronto, Sydney, San Fransisco.

Jones, S.B. and W. Dani. 1998. Design of porous media for optimal gas and liquid fluxes to plant roots. Soil Science Soc. of Amer. J. 62(3) : 563-574.

Jury, W.A., W.R. Gardner and W.H. Gardner. 1991. Soil Physics. 5th ed. John Wiley and Sons, Inc. New York.

Nimmo, J.R. 1997. Modelling structural influences on soil water retention. Soil Science Soc. of Amer. J. 61(3) : 712-719.

Thomson, L.M. and F.R. Troeh. 1978. Soil and Soil Fertility. Tata MacGraw - Hill Publishing Company Ltd., New Delhi. 